\title{
A Comparison of the Risk for Chronic Fascioliasis between Children 3 to 5 Years and Children 6 to 12 Years of Age in the Cusco Region of Peru
}

\author{
Melinda B. Tanabe, ${ }^{1}$ Maria A. Caravedo, ${ }^{1}$ Maria L. Morales, ${ }^{2}$ Martha Lopez, ${ }^{2}$ A. Clinton White Jr., ${ }^{1}$ Benicia Baca-Turpo, ${ }^{2}$ \\ Eulogia Arque, ${ }^{2}$ and Miguel M. Cabada ${ }^{1,2 *}$ \\ ${ }^{1}$ Division of Infectious Diseases, Department of Internal Medicine, University of Texas Medical Branch, Galveston, Texas; ${ }^{2}$ Universidad Peruana \\ Cayetano Heredia and University of Texas Medical Branch Collaborative Research Center, Cusco, Peru
}

\begin{abstract}
School-age children bear the highest burden of fascioliasis in endemic countries. Few studies have addressed Fasciola in preschool children. We performed a secondary data analysis using two Fasciola databases from Cusco, Peru, comparing preschoolers with elementary school children. We included 2,630 children, $50 \%$ were female, the median age was 8.4 years (interquartile range [IQR] 6.1-10.5), and 15\% $(396 / 2,630)$ were $<5$ years of age. Children $<5$ years were less likely to be infected with Fasciola hepatica $(P=0.008)$ and Hymenolepis nana $(P<0.001)$ and more likely to have anemia $(P<0.001)$ and a lower median height for age $Z(H A Z)$ score $(P=0.002)$. Fascioliasis was less common in younger children, but this group may be at higher risk for chronic complications caused by fascioliasis.
\end{abstract}

Fascioliasis in South America is a foodborne zoonosis caused by Fasciola hepatica. Infections in the highlands of Bolivia, Ecuador, and Peru account for almost half of all fascioliasis cases worldwide. ${ }^{1}$ In these endemic countries, schoolage children bear the highest burden of the disease. ${ }^{2,3}$ Among 3,000 children studied in the Cusco region of Peru, older children were more likely to be infected than younger children. ${ }^{4}$

Children less than 5 years of age are usually not reached by school-based fascioliasis control programs and are underrepresented in Fasciola studies. Ve et al., reported a case series of 4 children under 4 years with fascioliasis in Vietnam. In their review of the literature, the authors only found 38 reports of infected children less than 4 years old. ${ }^{5}$ Younger children may be more vulnerable to fascioliasis complications such as anemia and weight loss, which have a large impact during this critical developmental stage. ${ }^{3}$ Thus, further characterization of fascioliasis in this population is urgently needed. The aim of this study was to compare the prevalence and risk factors for fascioliasis in children under 5 years old to older children.

We performed secondary data analysis pooling the databases from two Fasciola studies in the Cusco region of Peru. ${ }^{4}$ We selected children $3-12$ years old with stool microscopy results for helminth infections and complete blood counts. Children were enrolled in three districts (Anta, Zurite, and Ancahuasi) from the Anta province and one district (Huancarani) from the Paucartambo province in the Cusco region of Peru. Information on age, sex, location of the household, education of the parents, height for age Z (HAZ) score, complete blood counts, and stool microscopy using the Kato-Katz and Lumbreras rapid sedimentation for gastrointestinal helminths were used for the analysis. The diagnosis of chronic Fasciola infection was defined as the presence of the parasite eggs in at least one stool sample. The 2007 WHO growth standards and criteria were used to define stunting. ${ }^{6}$ Hemoglobin values were adjusted for chronic high-altitude exposure using the CDC formula and anemia was defined according to WHO age- and sex-adjusted cutoffs. ${ }^{7}$ The Statistical Package

\footnotetext{
*Address correspondence to Miguel M. Cabada, Division of Infectious Diseases, Department of Internal Medicine, University of Texas Medical Branch, 301 University Blvd RT 0435,
} Galveston, TX 77555. E-mail: micabada@utmb.edu for the Social Sciences version 25.0 software (SPSS, Inc., Chicago, IL) was used for the statistical analysis; two tail $P$ values $<0.05$ were considered statistically significant. Under 5 and 5- to 12-year-old groups were compared using the $\chi^{2}$ and the Mann-Whitney $U$ tests for categorical and continuous variables. Both studies were reviewed by the Institutional Ethics Committee of Universidad Peruana Cayetano Heredia (\#60574) and the University of Texas Medical Branch (\#12099 and \#13-080).

The combined databases had 3,270 complete records including 2,630 records from children 3 to 12 years old. Half $(1,318 / 2,630,50.1 \%)$ were female, the median age was 8.4 (interquartile range [IQR] 6.1-10.5) years, and $15.1 \%(396 / 2,630)$ were under 5 years of age (Table 1$)$. The median years of education of the mothers was 6 years (IQR $3-10)$. One in four children $(672 / 2,630,25.6 \%)$ had at least one helminth infection and $3.7 \%(98 / 2,630)$ had two or more helminths. The most common helminth infections were Hymenolepis nana $(389 / 2,630,14.8 \%)$ followed by Ascaris lumbricoides (156/2,630, 5.9\%) and F. hepatica (148/2,630, 5.6\%). Strongyloides stercoralis $(45 / 2,630$, $1.7 \%)$, Trichuris trichiura $(26 / 2,630,1 \%)$, and hookworm $(17 / 2,630,0.6 \%)$ were less common. The median HAZ score was -1.34 (IQR -0.76 to -1.97$)$ and $23.6 \%(615 / 2,605)$ of the children met criteria for stunting. The mean altitudecorrected hemoglobin was $12.4 \mathrm{~g} / \mathrm{dL}( \pm 1.1)$ and $13.3 \%$ $(345 / 2,586)$ of the children had anemia.

The mothers of children under 5 had higher median years of education than the mothers of the older children (9 years [IQR 5-11] versus 6 years [IQR 3-10], $P<0.001$ ) (Table 1). Children under 5 were less likely to be infected with $F$. hepatica ([11/396] versus [137/2,234], odds ratio $[\mathrm{OR}]=0.43$ [95\% Cl 0.23-0.81], $P=0.008)$ and $H$. nana $([28 / 396]$ versus [361/2,234], OR $=$ 0.39 [95\% Cl $0.26-0.58], P<0.001)$. No other significant differences in the prevalence of helminth infections were found between age groups. The median-corrected hemoglobin of children under 5 was lower than that of older children (11.6 $\mathrm{g} / \mathrm{dL}$ [IQR 11.05-12.25] versus $12.5 \mathrm{~g} / \mathrm{dL}$ [IQR 11.8-13.1], $P$ $<0.001)$. Children under 5 were more likely than older children to have anemia ([96/383] versus [249/2,203], OR $=2.62$ [95\% $\mathrm{Cl}$ 2.01-3.42], $P<0.001)$. The median HAZ score was lower in children under 5 years old $(-1.52$ [IQR -0.9 to -2.07 ] versus -1.32 [IQR -0.74 to -1.94 ], $P=0.002$ ). 
TABLE 1

Demographics and characteristics of children $<5$ years old and $>5$ years old

\begin{tabular}{|c|c|c|c|c|c|}
\hline \multirow{2}{*}{ Characteristic } & & \multicolumn{3}{|c|}{$N(\%)$} & \multirow[b]{2}{*}{$P^{\star}$} \\
\hline & & Total & $<5$ years & $5-12$ years & \\
\hline \multirow{2}{*}{ Sex } & Female & $1,318(50.1)$ & 194 (49\%) & $1,124(50.3)$ & 0.672 \\
\hline & Male & $1,312(49.9)$ & $202(51)$ & $1,110(49.7)$ & \\
\hline \multirow[t]{4}{*}{ District } & Anta & $1,255(47.7)$ & $184(46.5)$ & $1,071(47.9)$ & 0.069 \\
\hline & Ancahuasi & 806 (30.6) & 108 (27.3) & 698 (31.3) & \\
\hline & Zurite & 297 (11.3) & 51 (12.8) & $246(11)$ & \\
\hline & Huancarani & 272 (10.3) & 53 (13.4) & 219 (9.8) & \\
\hline \multirow[t]{2}{*}{ Prior anemia treatment } & Yes & $242(9.7)$ & 51 (13.9) & $191(9)$ & 0.004 \\
\hline & No & $2,241(90.3)$ & $315(86.1)$ & $1,924(91)$ & \\
\hline \multirow[t]{2}{*}{ Prior malnutrition treatment } & Yes & $145(5.8)$ & $43(11.7)$ & $102(4.8)$ & $<0.001$ \\
\hline & No & 2,336 (94.2) & 325 (88.3) & $2,011(95.2)$ & \\
\hline \multirow[t]{2}{*}{ Prior parasite treatment } & Yes & $460(18.6)$ & 87 (23.6) & $373(17.7)$ & 0.007 \\
\hline & No & $2,015(81.4)$ & 281 (76.4) & $1,734(82.3)$ & \\
\hline \multirow[t]{2}{*}{ Anemia } & Yes & 345 (13.3) & $96(25.1)$ & 249 (11.3) & $<0.001$ \\
\hline & No & $2,241(86.7)$ & 287 (74.9) & $1,954(88.7)$ & \\
\hline \multirow[t]{3}{*}{ Stunting } & Yes & 615 (23.6) & $109(27.7)$ & 506 (22.9) & 0.037 \\
\hline & No & $1,990(75.7)$ & $284(72.3)$ & $1,706(77.1)$ & \\
\hline & & & Mean ( \pm SD) & & \\
\hline \multicolumn{2}{|l|}{ Characteristic } & Total & $<5$ years & $5-12$ years & $P \dagger$ \\
\hline \multirow{6}{*}{\multicolumn{2}{|c|}{$\begin{array}{l}\text { Altitude corrected hemoglobin }(\mathrm{g} / \mathrm{dL}) \\
\text { Platelets } \times 10^{3} \\
\text { Total white cell count } \times 10^{3} \\
\text { Height for age Z score } \\
\text { Years of school of the mother } \\
\text { Years of school of the father }\end{array}$}} & $12.4( \pm 1.06)$ & $11.6( \pm 1.0)$ & $12.5( \pm 1.0)$ & $<0.001$ \\
\hline & & $355.4( \pm 75.8)$ & $379.2( \pm 78.9)$ & $351.2( \pm 74.5)$ & $<0.001$ \\
\hline & & $7.4( \pm 2.6)$ & $8.1( \pm 4.6)$ & $7.2( \pm 2.1)$ & $<0.001$ \\
\hline & & $-1.34( \pm 0.9)$ & $-1.49( \pm 1.1)$ & $-1.32( \pm 0.95)$ & 0.002 \\
\hline & & $6.45( \pm 3.7)$ & $7.9( \pm 3.7)$ & $6.19( \pm 3.7)$ & $<0.001$ \\
\hline & & $7.87( \pm 3.4)$ & $8.7( \pm 3.4)$ & $7.72( \pm 3.4)$ & $<0.001$ \\
\hline
\end{tabular}

${ }^{*} \chi^{2}$ test.
†Student's $t$-test.

Among children under 5, children from Huancarani were more likely to be infected with Fasciola than children from other districts $(4 / 53$ versus $7 / 343, \mathrm{OR}=3.91[95 \% \mathrm{Cl}$ 1.1-13.87], $P=0.046$ ) (Table 2). In addition, the mothers of children with Fasciola infection had fewer years of education (6 years [IQR 2-9] versus 9 years [IQR 6-11], $P=0.042$ ). There were no differences by sex $(P=0.372)$, anemia prevalence $(P=0.478)$, or other intestinal helminth infections between children with Fasciola and those not infected. Similarly, the median-corrected hemoglobin values $(P=0.127)$ and HAZ scores $(P=0.195)$ were not significantly different between children with fascioliasis and those without infection.

Children under 5 years had a higher prevalence of anemia and stunting than older children. During the first 5 years of life, neural plasticity is fundamental for cognitive development and disruptions of these processes can have long-term consequences. ${ }^{8}$ Local health authorities in Peru have established programs focused on decreasing anemia and malnutrition among children under 5 years that include water, sanitation, and hygiene education (WASH), iron and other dietary supplementation, and deworming. ${ }^{9}$ Programs focused on WASH to improve nutritional status in children under 5 years have shown inconsistent effectiveness. ${ }^{10,11}$ In addition, high coverage and compliance with nutritional supplementation have been difficult to attain especially in rural areas of Peru. ${ }^{9}$

In our study, one in every four children had a helminth infection. The most common helminths were $H$. nana, A. lumbricoides, and $F$. hepatica. The first two parasites are associated with fecal oral transmission and suggest significant contamination of the environment with human feces. The prevalence of Ascaris and hookworm infection was low, which may reflect ongoing school-based deworming. However, current deworming programs do not address the most common parasites found here such as $F$. hepatica and $H$. nana. Although transmission of $F$. hepatica is not fecal-oral, the lack of access to safe water may be associated with increased risk and the contamination of the environment with Fasciola eggs may help maintain the life cycle of the parasite in the community. ${ }^{5,12}$ We found a significantly lower prevalence of Fasciola infection in children $<5$ years old in endemic areas of Cusco. This observation is similar to other studies on fascioliasis with a peak prevalence in school age children. ${ }^{2,13}$ Fasciola infection in children under 5 years was associated with living in Huancarani and less years of education of the parents, likely from precarious hygiene practices. ${ }^{14}$

There are some limitations to our study. The number of children under 5 years included in this study was low and may have limited the power to detect differences between the Fasciola infected and uninfected groups. We pooled data collected from studies performed at different time points with potential differences in local interventions to prevent malnutrition and parasite infections. Larger studies, adequately powered, specifically involving children under 5 years, are needed to confirm our findings.

In summary, our results demonstrate that children under 5 years old had a higher prevalence of malnutrition and anemia, but a lower prevalence of Fasciola and Hymenolepis infections. Given the vulnerability of children during the first years of life, these parasite infections and the socioeconomic factors that increase the risk of impaired development must be addressed by local authorities. Further research about the determinants and impact of fascioliasis in preschool children 
TABLE 2

Characteristics of children $<5$ years old with and without fascioliasis

\begin{tabular}{|c|c|c|c|c|c|}
\hline \multirow[b]{2}{*}{ Characteristic } & & \multicolumn{3}{|c|}{$N(\%)$} & \multirow[b]{2}{*}{$P^{*}$} \\
\hline & & Total & Fasciola $(+)$ & Fasciola (-) & \\
\hline \multirow[t]{2}{*}{ Sex } & Female & 194 (49) & $7(63.6)$ & $187(48.7)$ & 0.324 \\
\hline & Male & $202(51)$ & $4(36.4)$ & 198 (51.4) & \\
\hline \multirow[t]{4}{*}{ District } & Anta & $184(46.5)$ & $6(54.5)$ & 178 (46.2) & 0.59 \\
\hline & Ancahuasi & $108(27.3)$ & $1(9.1)$ & $107(27.8)$ & \\
\hline & Zurite & 51 (12.9) & $0(0)$ & 51 (13.2) & \\
\hline & Huancarani & $53(13.4)$ & $4(36.4)$ & $49(12.7)$ & \\
\hline \multirow[t]{2}{*}{ Prior anemia treatment } & Yes & $51(13.9)$ & $2(18.2)$ & $49(13.7)$ & 0.654 \\
\hline & No & $317(86.1)$ & $9(81.8)$ & 308 (86.3) & \\
\hline \multirow[t]{2}{*}{ Prior malnutrition treatment } & Yes & $43(11.7)$ & $6(54.5)$ & $37(10.4)$ & $<0.001$ \\
\hline & No & 325 (88.3) & $5(45.5)$ & $320(89.6)$ & \\
\hline \multirow[t]{2}{*}{ Prior parasite treatment } & Yes & $87(23.6)$ & $2(18.2)$ & $85(23.8)$ & 1 \\
\hline & No & 281 (76.4) & $9(81.8)$ & 272 (76.2) & \\
\hline \multirow[t]{2}{*}{ Anemia } & Yes & $96(27.7)$ & $4(36.4)$ & $92(24.7)$ & 0.478 \\
\hline & No & 287 (74.9) & 7 (63.6) & 280 (75.3) & \\
\hline \multirow[t]{3}{*}{ Stunting } & Yes & $109(27.7)$ & $5(45.5)$ & $104(27.2)$ & 0.183 \\
\hline & No & $284(72.3)$ & $6(54.5)$ & $278(72.8)$ & \\
\hline & & & Mean $( \pm S D)$ & & \\
\hline \multicolumn{2}{|l|}{ Characteristic } & Total & Fasciola $(+)$ & Fasciola $(-)$ & $P+$ \\
\hline \multicolumn{2}{|c|}{ Age (years) } & $4.1( \pm 0.5)$ & $3.8( \pm 0.7)$ & $4.1( \pm 0.5)$ & 0.088 \\
\hline \multicolumn{2}{|c|}{ Altitude corrected hemoglobin (g/dL) } & $11.6( \pm 1.0)$ & $11.1( \pm 0.8)$ & $11.6( \pm 1)$ & 0.111 \\
\hline \multicolumn{2}{|c|}{ Platelets $\times 10^{3}$} & $379.2( \pm 78.9)$ & $323.2( \pm 90)$ & $380.9( \pm 78.1)$ & 0.017 \\
\hline \multicolumn{2}{|l|}{ Total white cell count $\times 10^{3}$} & $8.1( \pm 4.6)$ & $7.3( \pm 1.9)$ & $8.1( \pm 4.6)$ & 0.606 \\
\hline \multicolumn{2}{|l|}{ Absolute eosinophil count } & $313( \pm 554)$ & $530( \pm 389)$ & $306( \pm 557)$ & 0.188 \\
\hline \multicolumn{2}{|l|}{ Height for age $Z$ score } & $-1.49( \pm 1.1)$ & $-1.63( \pm 1)$ & $-1.48( \pm 1.11)$ & 0.655 \\
\hline \multicolumn{2}{|l|}{ Weight for age $Z$ score } & $-0.51( \pm 0.85)$ & $-0.70( \pm 0.65)$ & $-0.51( \pm 0.86)$ & 0.457 \\
\hline \multicolumn{2}{|l|}{ Years of school of the mother } & $7.9( \pm 3.7)$ & $5.6( \pm 3.6)$ & $8.0( \pm 3.7)$ & 0.038 \\
\hline \multicolumn{2}{|l|}{ Years of school of the father } & $8.7( \pm 3.4)$ & $6.5( \pm 3.1)$ & $8.8( \pm 3.4)$ & 0.033 \\
\hline
\end{tabular}

and the safety of triclabendazole treatment in this age group are needed.

Received December 28, 2020. Accepted for publication May 13, 2021.

Published online July 19, 2021.

Financial support: This work was supported by the National Institute for Allergy and Infectious Diseases at the National Institutes of Health (grant number 1R01Al104820-01).

Disclaimer: The contents of this manuscript are solely the responsibility of the authors and do not necessarily represent the official views of the National Institute for Allergy and Infectious Diseases.

Authors' addresses: Melinda B. Tanabe, Maria A. Caravedo, and A. Clinton White Jr., Division of Infectious Diseases, Department of Internal Medicine, University of Texas Medical Branch, Galveston, TX, E-mails: mbtanabe@utmb.edu, macarave@utmb.edu, and acwhite@ utmb.edu. Maria L. Morales, Martha Lopez, Benicia Baca-Turpo, Eulogia Arque, and Miguel M. Cabada, Universidad Peruana Cayetano Heredia and University of Texas Medical Branch Collaborative Research Center, Cusco, Peru, E-mails: malu.morales.fernandez@ gmail.com, martlop2000@gmail.com, beniciabacat@gmail.com, picis_11_90@hotmail.com, and micabada@utmb.edu.

\section{REFERENCES}

1. Furst T, Keiser J, Utzinger J, 2012. Global burden of human foodborne trematodiasis: a systematic review and meta-analysis. Lancet Infect Dis 12: 210-221.

2. Esteban JG, Flores A, Aguirre C, Strauss W, Angles R, Mas-Coma $S, 1997$. Presence of very high prevalence and intensity of infection with Fasciola hepatica among Aymara children from the northern Bolivian Altiplano. Acta Trop 66: 1-14.

3. Cabada MM, Goodrich MR, Graham B, Villanueva-Meyer PG, Deichsel EL, Lopez M, Arque E, Clinton White A Jr, 2015.
Prevalence of intestinal helminths, anemia, and malnutrition in Paucartambo, Peru. Rev Panam Salud Publica 37: 69-75.

4. Cabada MM, Morales ML, Webb CM, Yang L, Bravenec CA, Lopez M, Bascope R, White AC, Gotuzzo E, 2018. Socioeconomic factors associated with Fasciola hepatica infection among children from 26 communities of the Cusco Region of Peru. Am J Trop Med Hyg 99: 1180-1185.

5. De NV, Le TH, Agramunt VH, Mas-Coma S, 2020. Early postnatal and preschool-age infection by Fasciola spp.: report of five cases from Vietnam and worldwide review. Am J Trop Med Hyg 103: 1578-1589.

6. WHO, 2006. WHO Child Growth Standards Length/Height-forAge, Weight-for-Age, Weight-for-Length, Weight-for-Height and Body Mass Index-for-Age: Methods and Development. Geneva, Switzerland: World Health Organization. Available at: https://www.who.int/publications/i/item/924154693X. Accessed November 24, 2020.

7. CDC, 1998. Current Trends CDC Criteria for Anemia in Children and Childbearing-Aged Women. Atlanta, GA: Centers for Disease Control and Prevention. Available at: https://www.cdc. $\mathrm{gov} / \mathrm{mmwr} / \mathrm{preview} / \mathrm{mmwrhtml} / 00001405 . \mathrm{htm}$. Accessed November 24, 2020.

8. Guerrant RL, Lima AAM, Moore SR, Lorntz B, Patrick P, 2004. Potential long-term consequences of early childhood enteric and parasitic infections. In: Institute of Medicine (US) Forum on Microbial Threats. The Infectious Etiology of Chronic Diseases: Defining the Relationship, Enhancing the Research, and Mitigating the Effects: Workshop Summary. Washington, DC: National Academies Press (US).

9. Ministerio de Salud, Peru, 2014. Plan Nacional para la Reduccioin de la Desnutricioin Croinica Infantil y la Prevencioin de la Anemia en el Paîs (2014-2016). Available at: http://bvs.minsa. gob.pe/local/MINSA/3514.pdf. Accessed December 9, 2020.

10. Gera T, Shah D, Sachdev HS, 2018. Impact of water, sanitation and hygiene interventions on growth, non-diarrheal morbidity and mortality in children residing in low- and middle-income countries: a systematic review. Indian Pediatr 55: 381-393. 
11. Humphrey JH et al., Sanitation Hygiene Infant Nutrition Efficacy (SHINE) Trial Team, 2019. Independent and combined effects of improved water, sanitation, and hygiene, and improved complementary feeding, on child stunting and anaemia in rural Zimbabwe: a cluster-randomised trial. Lancet Glob Health 7: e132e147.

12. Nematian J, Nematian E, Gholamrezanezhad A, Asgari AA, 2004. Prevalence of intestinal parasitic infections and their relation with socio-economic factors and hygienic habits in Tehran primary school students. Acta Trop 92: 179-186.
13. González LC, Esteban JG, Bargues MD, Valero MA, Ortiz P, Náquira C, Mas-Coma S, 2011. Hyperendemic human fascioliasis in Andean valleys: an altitudinal transect analysis in children of Cajamarca province, Peru. Acta Trop 120: 119-129.

14. Quihui L, Valencia ME, Crompton DW, Phillips S, Hagan P, Morales G, Díaz-Camacho SP, 2006. Role of the employment status and education of mothers in the prevalence of intestinal parasitic infections in Mexican rural schoolchildren. BMC Public Health 6: 225. 